\title{
The Imprinted Gene Peg3 Is Not Essential for Tumor Necrosis Factor $\alpha$ Signaling
}

\author{
Elizabeth C. Ledgerwood, Stephen O'Rahilly, and M. Azim Surani \\ Departments of Clinical Biochemistry and Medicine (ECL, SOR), University of Cambridge, Addenbrooke's Hospital, \\ Cambridge, and Wellcome CRC Institute of Cancer and Developmental Biology (MAS), University of Cambridge, \\ Cambridge, United Kingdom
}

SUMMARY: The imprinted gene Peg3 encodes a zinc-finger protein which has been proposed to be involved in tumor necrosis factor $\alpha$ (TNF) signaling via an interaction with TNF receptor-associated factor 2 (TRAF2). Primary embryonic fibroblasts derived from mice with a null mutation in Peg3 showed no abnormalities in TNF-induced nuclear translocation of nuclear factor $x \mathrm{~B}$ (NF- $x \mathrm{~B}$ ) or phosphorylation of the mitogen-activated protein kinases, extracellular signal-regulated kinases 1 and 2, $c$-Jun $\mathrm{N}$-terminal kinase/stress-activated protein kinase (JNK/SAPK), and p38. In addition, the loss of Peg3 function did not increase the sensitivity of the cells to the cytotoxic action of TNF. These results suggest that Peg3 does not play an essential role in TNF signal transduction. (Lab Invest 2000, 80:1509-1511).

\begin{abstract}
$P^{\mathrm{e}}$ eg3 is an imprinted gene which is expressed exclusively from the paternal chromosome (Kuroiwa et al, 1996; Relaix et al, 1996). It encodes a predicted 1572 residue zinc finger protein of unknown function. Peg3 is expressed predominantly in the brain of adult mice with more widespread expression in embryonic tissues (Kuroiwa et al, 1996; Relaix et al, 1996). Relaix et al (1998) recently proposed that Peg3 is intimately involved with the intracellular signal transduction pathways activated by tumor necrosis factor $\alpha$ (TNF). TNF is a pleiotropic cytokine playing a pivotal role in immune and inflammatory regulation, primarily through activation of gene expression via the transcription factors, nuclear factor $x \mathrm{~B}\left(\mathrm{NF}-\chi_{\mathrm{B}}\right)$ and activator protein 1 (AP-1). These pathways are critical for the proinflammatory and anti-apoptotic actions of TNF (Baeuerle, 1998; Fiers, 1991; Roulston et al, 1998; van Antwerp et al, 1998). TNF triggers a cascade of intracellular signaling events, after binding to two cell surface receptors (TNF receptors 1 and 2), with subsequent recruitment of cytoplasmic signaling molecules (Ledgerwood et al, 1999). TNF triggers activation of the NF- $x$ B-inducing kinase (NIK) leading to NF- $x$ B activation, phosphorylation of the mitogen-activated protein (MAP) kinases leading to activation of AP-1 (Eder, 1997), and activation of caspases leading to apoptosis (Yuan, 1997). After TNF stimulation, TNF receptor-associated factor 2 (TRAF2) is recruited to the intracellular domains of both TNF receptor 1-via the adaptor molecule TNF receptorassociated death domain protein (TRADD)—and TNF receptor 2. Early reports based on overexpression stud-
\end{abstract}

Received April 17, 2000.

This study was supported by the Wellcome Trust.

Address reprint requests to: Dr. E. C. Ledgerwood, Department of Biochemistry, University of Otago, P.O. Box 56, Dunedin, New Zealand. Fax: 64 3 4797866; E-mail: lizl@sanger.otago.ac.nz ies suggested that TRAF2 coupled TNF to NF- $x$ B activation. However, data from TRAF2-null mice has challenged this concept. Thus, cells derived from TRAF2-null mice show only minor abnormalities in TNF-induced $\mathrm{NF}-x \mathrm{~B}$ activation, but complete disruption of TNFstimulated phosphorylation of $c$-Jun N-terminal kinase/ stress-activated protein kinase (JNK/SAPK) (Lee et al, 1997; Yeh et al, 1997).

Relaix et al (1998) demonstrated that Peg3 physically interacted with TRAF2, suggesting it could be involved in TNF signaling. In transfection studies, $\mathrm{Peg} 3$ activated an $\mathrm{NF}-x \mathrm{~B}$ reporter construct, and a dominant-negative Peg3 construct inhibited TNF-induced activation of NFxB. Furthermore, Peg3 was reported to protect cells from the cytotoxic effect of TNF.

Recently mice have been generated with a null mutation in Peg3. The female mice show aberrant maternal behavior with neglect of pups (Li et al, 1999). To test the hypothesis that Peg3 is involved in TNF signaling, we have used primary embryonic fibroblasts (PEFs) and neuronal cells derived from mice with the Peg3 null mutation to determine the effect on TNFinduced nuclear translocation of NF- $x \mathrm{~B}$, phosphorylation of MAP kinases, and cell death.

\section{Results and Discussion}

To assess whether Peg3 is essential for TNF signaling, we used cells derived from mice with the Peg3 null mutation and compared them with cells derived from wild-type controls. The mutant allele contains the lac $Z$ reporter gene, and $\beta$-galactosidase staining was used to assess whether particular cell types normally express Peg3. PEFs at passages 2 and 3 (but not later passages) showed clear $\beta$-galactosidase staining in the majority of cells, and these cells were used to assess the effect of the null mutation on TNF signaling. 


\section{Nuclear Translocation of NF-xB in Response to TNF}

In unstimulated cells, NF- $x \mathrm{~B}$ is sequestered in the cytoplasm by $\mathrm{I} x \mathrm{~B}$. Following activation, $\mathrm{I} x \mathrm{~B}$ is phosphorylated, polyubiquinated, and degraded, thus unmasking the NF- $x \mathrm{~B}$ nuclear localization signal. Once in the nucleus, NF- $x \mathrm{~B}$ stimulates transcription of a range of TNF-responsive genes. Using immunofluorescence microscopy, we assessed the effect of the loss of Peg3 function on TNF-induced nuclear translocation of NF$\varkappa \mathrm{B}$. Wild-type and mutant cells were incubated with TNF for 0 hours, 10 minutes, 20 minutes, 30 minutes, 1 hour, and 2 hours before immunostaining with an anti-NF- $x \mathrm{~B}$ antibody. In both cell types, maximum nuclear translocation occurred at 20 minutes, and at this time point, over $90 \%$ of cells showed nuclear localization of NF- $x \mathrm{~B}$ (Fig. 1). There was no apparent difference between the wild-type and mutant cells in the extent of staining at any time point examined. This suggested that Peg3 is not an essential component of the signaling pathway between TNF and the nuclear translocation of NF- $x \mathrm{~B}$.

The brain is a major site of Peg3 expression in the neonate and adult. Therefore, we also investigated whether there was a neuronal cell-specific loss of TNF-induced NF- $x \mathrm{~B}$ nuclear translocation in primary cells derived from hypothalami of new-born Peg3 mutant mice compared to the wild-type control. Neither wild-type nor mutant neuronal cells, identified by co-staining with an antibody against $\beta$-tubulin III, showed nuclear translocation of $\mathrm{NF}-x \mathrm{~B}$ in response to TNF. However, nonneuronal cells from both wild-type and mutant animals in the same culture responded identically to TNF (data not shown).

\section{Phosphorylation of MAP Kinases in Response to TNF}

The role of TRAF2 in TNF signaling has been reassessed following the generation of TRAF2-null mice (Lee et al, 1997; Yeh et al, 1997). Thus, cells derived from TRAF2-null mice show only minor abnormalities in TNF-induced NF- $x$ B activation but complete disruption of TNF-stimulated phosphorylation of JNK/
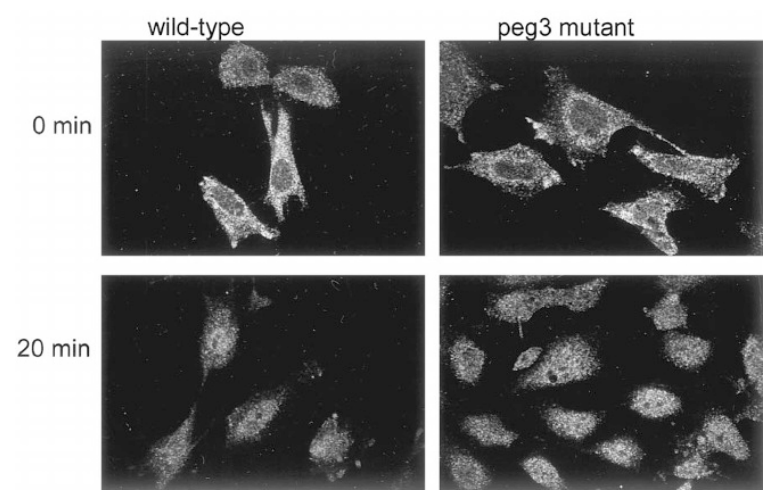

Figure 1.

Tumor necrosis factor (TNF)-induced nuclear translocation of NF- $\varkappa$ B. Wildtype (left-hand panel) and mutant (right-hand panel) primary embryonic fibroblasts (PEFs) stimulated with $100 \mathrm{ng} / \mathrm{ml}$ murine TNF for 0 and 20 minutes and immunostained with rabbit anti-NF- $\varkappa$ B p65 and a FITC-conjugated secondary antibody.
SAPK. Because Peg3 was reported to interact with TRAF2, we determined whether the loss of Peg3 function in PEFs impaired TNF-induced phosphorylation of the MAP kinases (extracellular signal-regulated kinases 1 and 2), JNK/SAPK, and p38 (Fig. 2). No differences were seen in either the time course or extent of phosphorylation of these protein kinases between the wild-type and mutant cells.

\section{Effect of the Peg3 Null Mutation on the Sensitivity of PEFs to TNF-Induced Cell Death}

Although TNF can induce cell death in a variety of cell types, this generally requires the inhibition of ongoing protein synthesis in nontransformed cells (Beyaert and Fiers, 1994). The resistance to TNF-induced killing is thought to be due to activation of anti-apoptotic genes through the transcription factors $\mathrm{NF}-x \mathrm{~B}$ and $\mathrm{AP}-1$. If signaling to either of these transcription factors is disrupted, cells may become sensitive to TNFinduced death. Indeed, cells derived from the TRAF2 knockout mice show increased sensitivity to TNFinduced death in the absence of protein synthesis inhibitors (Lee et al, 1997; Yeh et al, 1997).

Wild-type and mutant PEFs were treated with $10 \mathrm{ng} / \mathrm{ml}$ TNF, and the extent of cell death was determined by staining with propidium and iodide and fluorescenceactivated cell sorting (FACS) analysis. Both cell types were found to be completely resistant to TNF-induced death for up to 48 hours, suggesting that Peg3 is not necessary for protection against the cytotoxic action of TNF.

In summary, in primary embryonic fibroblasts, a cell type which normally expresses Peg3, the absence of Peg3 has no effect on TNF signaling to NF- $x B$ and the MAP kinases upstream of AP-1. Furthermore, the Peg3 null cells are not sensitized to TNF-induced cytotoxicity. These findings do not support the conclusions of Relaix et al (1998) that Peg3 is a regulator of TNF signaling. We cannot rule out the possibility that Peg3 plays a tissuespecific role in TNF responses. Alternatively, the observed interaction between Peg3 and TRAF2, although irrelevant for TNF signaling, may be critical for signaling by other TRAF2-interacting ligand/receptor systems, eg, CD40 (Arch et al, 1998). Our data indicate that Peg3 is not essential for at least three of the key intracellular events mediating the actions of TNF.

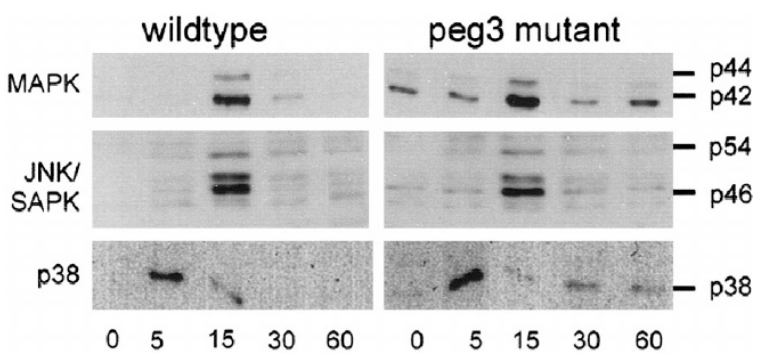

Figure 2.

TNF-induced phosphorylation of mitogen-activated protein (MAP) kinases. Wild-type (left-hand panel) and mutant (right-hand panel) PEFs treated with 50 $\mathrm{ng} / \mathrm{ml}$ mTNF were immunoblotted with anti-ACTIVE MAP kinase, anti-ACTIVE JNK/SAPK, or anti-phospho p38 MAP kinase. Incubation time is in minutes. The sizes of the kinase isoforms in $\mathrm{kDa}$ are indicated on the right. 


\section{Materials and Methods}

\section{Cell Culture}

Cells were derived from mice carrying a null mutation in the Peg3 gene and their wild type controls ( $\mathrm{Li}$ et al, 1999). Primary embryonic fibroblasts derived from E12.5 embryos were cultured in DMEM/10\% fetal bovine serum (FBS) and used at passages 2 and 3. To identify cells containing the Peg3 null mutation, $\beta$-galactosidase staining was performed as described (Li et al, 1999). Cells were isolated from the hypothalami of newborn mice and cultured in DMEM:HamsF12 (1:1)/2\% B27/1\% FBS on plates coated with poly-Llysine $(0.1 \mathrm{mg} / \mathrm{ml})$. The neuronal cells were identified by immunostaining with anti-mouse- $\beta$-tubulin III (Sigma, Pode, Dorset, United Kingdom).

\section{Immunofluorescence Microscopy of NF-xB Nuclear Translocation}

Cells were cultured on glass coverslips and stimulated with $100 \mathrm{ng} / \mathrm{ml}$ murine TNF (Autogen Bioclear, Calne, Wilts, United Kingdom) in serum-containing medium at $37^{\circ} \mathrm{C} / 5 \% \mathrm{CO}_{2}$. After treatment the cells were fixed (2\% paraformaldehyde, 4 minutes), permeabilized (100\% methanol, 10 minutes, $-20^{\circ} \mathrm{C}$ ), and immunostained with rabbit anti-NF- $x$ B p65 (Santa Cruz Biotechnologies, Santa Cruz, California) and an FITCconjugated secondary antibody (Sigma). Monolayers were viewed using a Nikon Optiphot-II microscope (Nikon, Tokyo, Japan) coupled to a Biorad MRC1000 confocal attachment and COMOS software (BioRad Laboratories, Hemel Hempstead, United Kingdom).

\section{Analysis of MAP Kinase Phosphorylation}

Cells were cultured in serum-free medium for 24 hours before treatment with $50 \mathrm{ng} / \mathrm{ml} \mathrm{mTNF}$ in serum-free medium at $37^{\circ} \mathrm{C} / 5 \% \mathrm{CO}_{2}$. After the incubation, the cells were placed on ice and lysed directly into ice-cold sample buffer (62.5 mM Tris.Cl, pH 6.8; 10\% glycerol, $2 \%$ SDS, $10 \%$ 2-mercaptoethanol). Equal amounts were analyzed by immunoblotting with anti-ACTIVE MAP kinase (Promega, Madison, Wisconsin), anti-ACTIVE JNK SAPK (Promega), or anti-phospho p38 MAP kinase (New England Biolabs, Beverly, Massachusetts). The presence of equal amounts of total kinases in each lane was confirmed by immunoblotting with the appropriate nonphospho-specific antibodies (not shown).

\section{Cell Death Assay}

PEFs were treated with $10 \mathrm{ng} / \mathrm{ml} \mathrm{mTNF}$ in serumcontaining medium for up to 48 hours at $37^{\circ} \mathrm{C} / 5 \%$ $\mathrm{CO}_{2}$. After the incubation, cells were washed with ice-cold PBS, detached with trypsin/EDTA, and stained with propidium iodide ( $2 \mu \mathrm{g} / \mathrm{ml}$ in PBS). The proportion of propidium iodide-positive cells was determined by flow cytometry on a FacSort (Becton Dickinson, Lincoln Park, New Jersey).

\section{Acknowledgements}

We thank K. Hilton and S.C. Barton for excellent technical support, M.A. Caldwell for advice on neuronal cell culture, and E.B. Keverne and Y.Y. Szeto for isolation of hypothalami and helpful discussions.

\section{References}

Arch RH, Gedrich RW, and Thompson CB (1998). Tumor necrosis factor receptor-associated factors (TRAFs) - a family of adapter proteins that regulates life and death. Genes Dev 12:2821-2830.

Baeuerle PA (1998). Pro-inflammatory signaling: Last pieces in the NF- $x$ B Puzzle? Curr Biol 8:R19-R22.

Beyaert R and Fiers W (1994). Molecular mechanisms of tumor necrosis factor-induced cytotoxicity. What we do understand and what we do not. FEBS Lett 340:9-16.

Eder J (1997). Tumour necrosis factor $\alpha$ and interleukin 1 signalling: Do MAPKK kinases connect it all? Trends Pharmacol Sci 18:319-322.

Fiers W (1991). Tumor necrosis factor: Characterization at the molecular, cellular and in vivo level. FEBS Lett 285:199-212.

Kuroiwa Y, Kaneko-Ishino T, Kagitani F, Kohda T, Li L-L, Tada M, Suzuki R, Yokoyama M, Shiroishi T, Wakana S, Barton SC, Ishino F, and Surani MA (1996). Peg3 imprinted gene on proximal chromosome 7 encodes for a zinc finger protein. Nat Genet 12:186-190.

Ledgerwood EC, Pober JS, and Bradley JR (1999). Recent advances in the molecular basis of TNF signal transduction. Lab Invest 79:1041-1050.

Lee SY, Reichlin A, Santana A, Sokol KA, Nussenzweig MC, and Choi Y (1997). TRAF2 is essential for JNK but not NF- $x$ B activation and regulates lymphocyte proliferation and survival. Immunity 7:703-713.

Li L-L, Keverne EB, Aparicio SA, Ishino F, Barton SC, and Surani MA (1999). Regulation of maternal behavior and offspring growth by paternally expressed Peg3. Science 284:330-333.

Relaix F, Wei X, Wu X, and Sassoon D (1998). Peg3/Pw1 is an imprinted gene involved in the TNF-NF- $x$ B signal transduction pathway. Nat Genet 18:287-291.

Relaix F, Weng X, Marazzi G, Yang E, Copeland N, Jenkins N, Spence SE, and Sassoon D (1996). Pw1, a novel zinc finger gene implicated in the myogenic and neuronal lineages. Dev Biol 177:383-396.

Roulston A, Reinhard C, Amiri P, and Williams LT (1998). Early activation of cJun $\mathrm{N}$-terminal kinase and p38 kinase regulate cell survival in response to tumor necrosis factor $\alpha$. J Biol Chem 273:10232-10239.

van Antwerp DJ, Martin SJ, Verma IM, and Green DR (1998). Inhibition of TNF-induced apoptosis by NF- $x$ B. Trends Cell Biol 8:107-111.

Yeh W-C, Shahinian A, Speiser D, Kraunus J, Billia F, Wakeham A, de la Pompa JL, Ferrick D, Hum B, Iscove N, Ohashi P, Rothe M, Goeddel DV, and Mak TW (1997). Early lethality, functional NF- $x$ B activation, and increased sensitivity to TNF-induced cell death in TRAF2-deficient mice. Immunity 7:715-725.

Yuan J (1997). Transducing signals of life and death. Curr Opin Cell Biol 9:247-251. 